\title{
Efficacy of Traditional and Improved Granaries in Protecting Maize from Prostephanus truncatus in Small Holder Farming Storage System in Makonde District, Zimbabwe
}

\author{
Mhiko Tinotenda Admire ${ }^{1, *}$, Shokora Tinashe ${ }^{2}$ \\ ${ }^{1}$ Genetics, Crop Production and Crop Protection, Peoples’ Friendship University of Russia, Moscow, Russia \\ ${ }^{2}$ Food Science and Post Harvest Technology, Chinhoyi University of Technology, Chinhoyi, Zimbabwe \\ *Corresponding author: tinomhiko@yahoo.co.uk
}

Received February 03, 2014; Revised February 19, 2014; Accepted March 24, 2014

\begin{abstract}
The study was carried out in Makonde District, located $17^{\circ} 21^{\prime} \mathrm{S}$ and $30^{\circ} 12^{\prime} \mathrm{E}$ in Mashonaland West Province to assess the efficiency of improved and traditional granaries in protecting traditional and hybrid maize from Prostephanus truncatus. Ten farmers were randomly selected from 20 wards in the District. Multistage cluster sampling and purposive sampling techniques were used. Amongst the 10 selected farmers, 5 were using traditional granaries and the other 5 were using improved granaries. Four farmers used in the study stored a traditional maize variety (Hickory King) and six farmers stored a hybrid variety (SC 513). Demographic data on the farmers was captured on a questionnaire which was conducted at the beginning of the study. The questionnaire had information on type of storage granary, age of farmers, type of stored maize variety, amount of maize stored, major prevalent pests and grain management practices. Hybrid and traditional maize varieties stored in selected improved and traditional granaries. The maize varieties were first fumigated for a week using phosphine tablets and granaries were first disinfected using Deltamethrin (2.4\% w.p) at $1.5 \mathrm{~g} / \mathrm{l}$ water at $20 \mathrm{ml} / \mathrm{m}^{2}$. Fumigated traditional and hybrid maize were then stored in disinfected granaries. Maize grains were stored for 6 months. Traditional, intermediate traditional, intermediate improved, improved granaries had 36\%, 16\%, 30\% and 18\% utilization amongst farmers respectively. Age of farmers showed a significant influence on the type of granary used to store their grain. Sitophilus zeamais, Prostephanus truncatus, Sitotroga cereallela were most prevalent insect species. The relative abundance of these pests in the granaries was $100 \%, 70 \%$ and $85 \%$ respectively. Hybrid maize (SC 513) was reinfested with Prostephanus truncatus after 3 months during storage in traditional granaries. The relative abundance of pests in a granary was influenced by the farmer duration of storage and the treatment. It was concluded that traditional granaries used by farmers were found to be prone to Prostephanus truncatus infestation as compared to improved granaries. There was a significant difference in the variations between granary type, maize variety and levels of Prostephanus truncatus infestation.
\end{abstract}

Keywords: Sitophilus zeamais, Prostephanus truncatus, Sitotroga cereallela, Makonde District Granary

Cite This Article: Mhiko Tinotenda Admire, and Shokora Tinashe, "Efficacy of Traditional and Improved Granaries in Protecting Maize from Prostephanus truncatus in Small Holder Farming Storage System in Makonde District, Zimbabwe.” World Journal of Agricultural Research, vol. 2, no. 2 (2014): 63-69. doi: 10.12691/wjar-2-2-6.

\section{Introduction}

In Zimbabwe, maize (Zea mays, L.) is the most produced grain cereal. It is the staple food for most households. Over $90 \%$ of the population in Southern African use maize as their staple diet (Wambugu, 2009; Zinyengere et al., 2011). Maize is also an important grain crop for animal feeding (Kapuya et al., 2011). According to FAO, maize accounted for $43 \%$ of the total dietary energy supply (DES) between 2003 and 2005 in Zimbabwe [4]. The average per capita food consumption of maize and maize products was $120 \mathrm{~kg} / \mathrm{year}$ between 2004 and 2008 [4]. About 70\% of the produced maize is stored on the farm for household consumption and farmlevel enterprises $[2,3,13]$. Safe storage of maize at the farm level is therefore crucial, as it directly impacts on poverty alleviation, food and income security, and prosperity for the small holder farmers [18]. In Zimbabwe, maize is packaged in polyethylene bags, jute bags, cotton wool packs, and stored in pole and dagga/mud granaries and silos [4].

After harvesting, most small holder farmers do not test the initial moisture content before grain storage. No fumigation is performed and they lack storage 
management skills and this result in high post harvest losses during storage. Small holder farmers throughout sub-Saharan Africa incur grain losses of their stored produce due to insect damage [17]. According to Kamanula et al storage insect pests cause $30 \%$ of the post harvest losses in grains in sub-Saharan Africa [8]. Small holder farmers usually have one harvest per year [17]. This single harvest may be subject to failure due to insufficient rains, mineral deficiency and pest infestation [18]. The major insect pests of stored maize in SubSaharan Africa include maize weevil (Sitophilus zeamais), rice weevil (Sitophilus oryzae), Larger Grain Borer (Prostephanus truncatus), Angoumois grain moth (Sitotroga cereallela), and lesser grain borer (Rhizopertha dominica) [8].

However, although many storage insect pests are ubiquitous throughout the Sub-Saharan Africa, the $P$. truncatus has been found to cause more than twice the weight loss in maize than infestations of indigenous pests such as S. zeamais [17]. The lack of suitable storage structures and the absence of storage management technologies often force the small holder farmers to sell their produce immediately after harvest [18]. According to Stathers et al, $P$. truncatus is an indigenous storage pest of Meso-America [17]. It is assumed to have been introduced in Tanzania through grain imports [6]. It has spread to neighboring countries and is now the most serious pest of stored maize in Africa. LGB was first detected in Zimbabwe in during the 2006/2007 storage season. The pest is also capable of destroying up to $34 \%$ of maize weight in three to six months during onset of grain storage [7]. Bulk of its population is widely distributed in alternative hosts such as dry twigs and tree branches. The pest is also capable of attacking and boring through the timber of stores and houses, and wooden utensils [7]. Results from the Plant Protection Research Institute of Zimbabwe showed that the most seriously affected areas in 2010 were Zvimba, Karoi, Chitomborwizi, Kadoma, Mhondoro, Murombedzi, and Bindura. In Karoi, the pest has been reported to have destroyed 20 tonnes of seed maize, while 53 tonnes stored maize were reduced to dust in Murombedzi [14].

\section{Results}

\subsection{The Most Commonly Used Granaries in Makonde District}

There was a 36\%, 16\%, 30\%, 18\% traditional, intermediate traditional, intermediate improved and improved granary used among farmers respectively (Table $1)$.

Table 1. Granaries in Makonde District

\begin{tabular}{ccc}
\hline Granary type & Description of structure & \% farmer who use the granary \\
\hline Traditional & Wooden pole and dagga walls & 36 \\
Intermediate traditional & Poles, dagga platforms and bricks & 16 \\
Intermediate improved & Concrete platforms, brick and asbestos roofs & 30 \\
Improved & Concrete platforms, bricks and thatched roof & 18 \\
\hline
\end{tabular}

\subsection{Interaction between Age, Sex and amount of Maize Stored in the Granaries}

There was a small significant difference in the granary types used by those below the age of 40 years. Traditional and intermediate improved granaries had the same frequency of usage by those below the age of 40 years. The least used granary by this age group was the intermediate traditional granary. There was a huge significant difference in the usage of different types of granaries by the age group of 40-65 years (Table 2). Intermediate improved granary was the mostly used granary which varied significantly with the second common granary in the age group which was the traditional granary. There was a small significant difference among the last three common granaries. Traditional granary varied significantly with the second common granary among those above the age of 65 years. A small significant difference still exist on the remaining three least used granaries, the intermediate traditional granary being the least in this category (Table 2) across the age groups, there was a huge significant difference among age groups who used the same type of granary. The traditional granary was the mostly used granary and the least used was the intermediate traditional granary (Table 2).

Generally there were more women who stored maize than men (Table 2). There was a slight significant difference between the most significantly used granaries by males than the second frequently used granary. However, there was a huge significant difference between those two and the least frequently used granaries (Table 2). On the other hand, there was a significant difference between the most commonly used granary by females and the second frequently used granary. Again there was a huge significant difference between these two and the least frequently used granaries (Table 2).

There was a huge significant difference between males and females who used traditional granaries (Table 2). There was also a huge significant difference between males and females who used intermediate granaries and in all cases females are predominating. There was a slight significant difference between the males and females who used intermediate improved granaries and females predominate again (Table 2). A huge significant difference existed among the females and males who used improved granaries.

There was a huge significant difference between farmers whore stored more than three tones and the rest of the farmers who practiced on-farm storage (Table 2). A huge significant difference also existed between farmers who store more than three tones in traditional granaries and the rest of the subjects in the study (Table 2). A slight significant difference was among the farmers who store different quantities in intermediate granaries (Table 2). There was a small significant difference among farmers who stored above one tone of maize in intermediate and 
those who stored more than one tone. The small significant difference also existed among farmers who stored varying quantities in improved granaries (Table 2). Generally, a small significant difference existed among farmers who stored different quantities in the different types of granaries, traditional granaries being the mostly used granaries (Table 2).

Table 2. Interaction between age, sex and the amount of seed stored at the farm

\begin{tabular}{|c|c|c|c|c|c|c|c|c|}
\hline \multirow[t]{2}{*}{ Granary type } & \multicolumn{3}{|c|}{ Age } & \multicolumn{2}{|c|}{ Sex } & \multicolumn{3}{|c|}{ Amount of grain stored (kg) } \\
\hline & $<40$ & $40-50$ & $>65$ & M & $\mathrm{F}$ & $<1$ & $1-3$ & $>3$ \\
\hline Traditional & 18 & 46 & 39 & 31 & 42 & 21 & 18 & 33 \\
\hline Intermediate Traditional & 12 & 45 & 4 & 11 & 21 & 11 & 9 & 12 \\
\hline Intermediate Improved & 18 & 29 & 13 & 27 & 33 & 12 & 2 & 26 \\
\hline Improved & 17 & 11 & 8 & 13 & 23 & 11 & 8 & 17 \\
\hline
\end{tabular}

2.3. The Most Prevalent Insect Pests of Stored Maize in Makonde District Prostephanus truncatus, Sitotroga cereallela was 100\%, $70 \%$ and $85 \%$ respectively, in all sampled storage granaries.

Table 3. Relative abundance of prevalent insect species and their average population per kilogram maize sample

\begin{tabular}{l} 
Insect pest \\
Sitophilus zeamais \\
Prostephanus truncatus \\
Sitotroga cereallela \\
\hline Re-infestation of Traditional and \\
2.4. Improved Granaries on by Insects after \\
Fumigation
\end{tabular}

Traditional granaries were re- infested by LGB after a period of three months in storage. Improved granaries were re-infested by LGB after four and half months of

kg sample

9

storage (Figure 1). Maize hybrid SC 513 was infested in both improved and traditional granaries.

\subsection{Influence of Famer, Storage Duration, and Storage Structure on the Number of Insects}

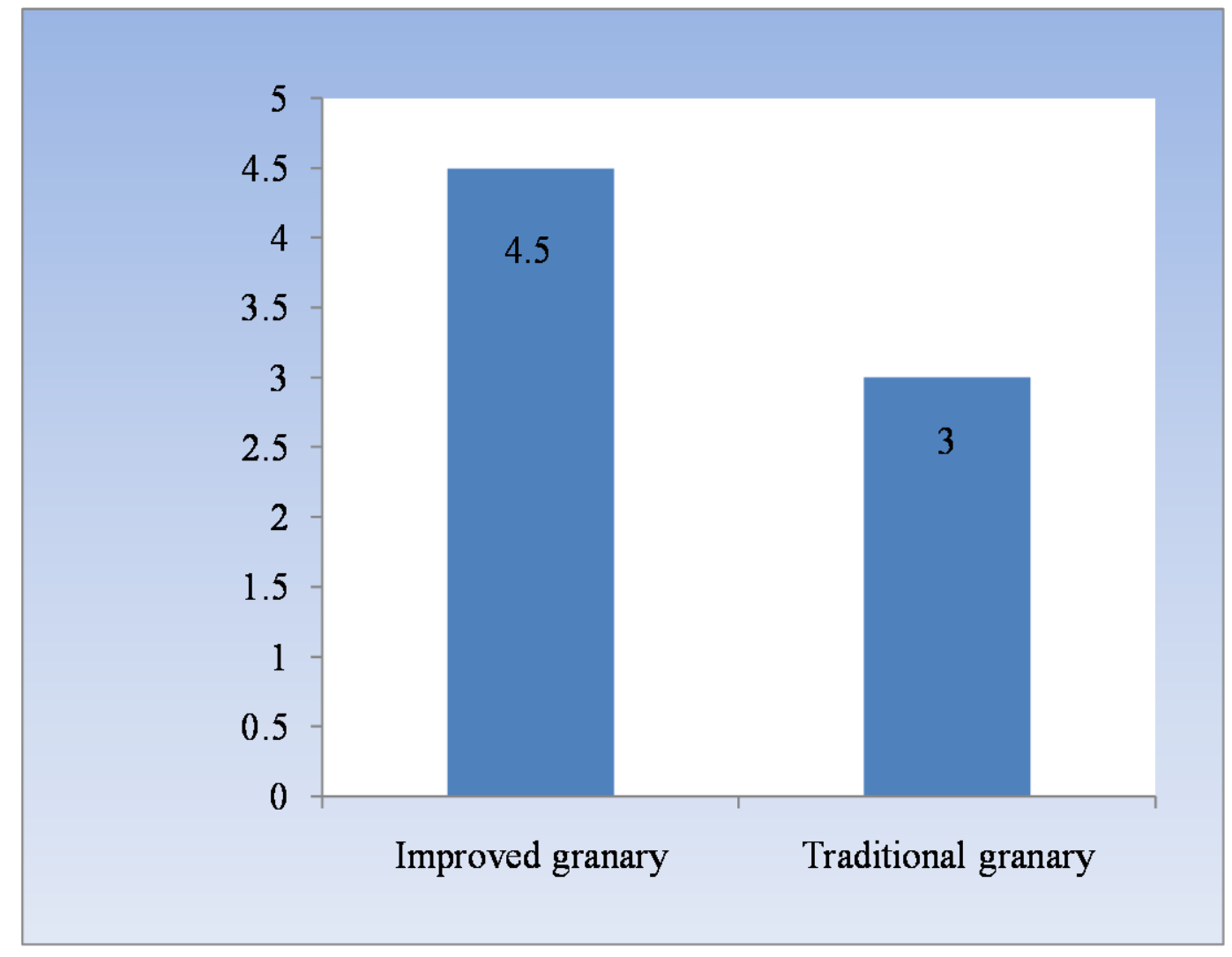

Figure 1. Period of re-infestation of grain with $P$. truncatus 
There was a 308 mean number of insects occurrence during storage (Table 4).

Table 4. Influence of famer, storage duration and storage structure on the number of insects

\begin{tabular}{|c|c|c|}
\hline Variable & Significance & Mean number of insects \\
\hline Farmer & 0.000 & 70 \\
\hline Duration of storage & 0.000 & 267 \\
\hline Type of granary & 0.000 & 308 \\
\hline Farmer*duration of storage & 0.901 & 4 \\
\hline Farmer $*$ type of granary & 0.034 & 16 \\
\hline Duration in storage*type of granary & & 27 \\
\hline Farmer*type of granary*duration of storage & 0.000 & 1 \\
\hline Error & 1.000 & 6 \\
\hline
\end{tabular}

2.6. The Rate of Increase of (P. truncatus) LGB in Improved and Traditional Granaries in Makonde District

Infestation was noted after three months after fumigation in improved and traditional granaries. There were 14 and 43 live infestation of (LGB) in traditional granaries at month 5 and 6.5 respectively after fumigation. There were 1 and 12 live infestation (LGB) in improved granaries at month 5 and 6.5 respectively after fumigation (Figure 2).

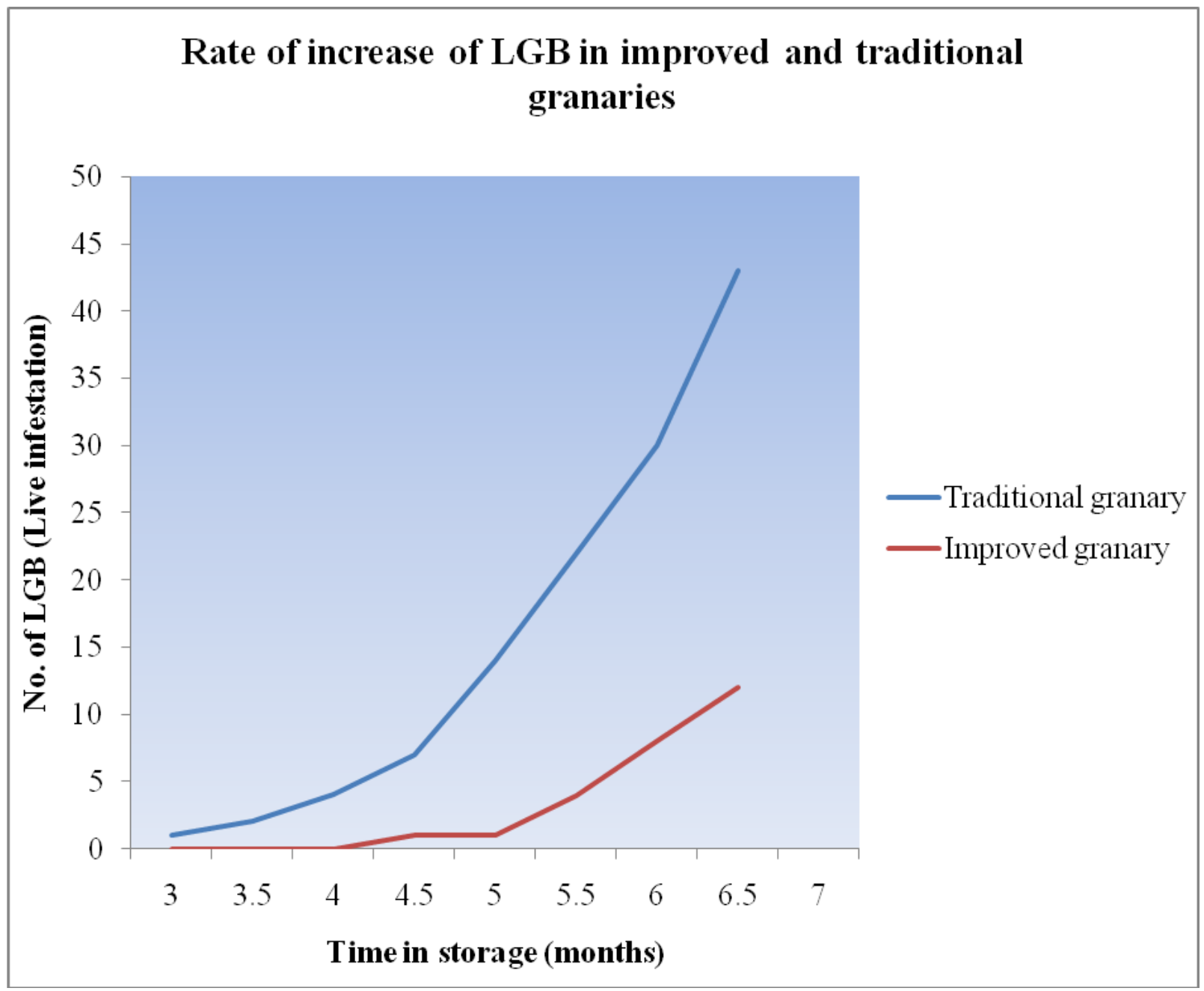

Figure 2. The rate of re-infestation of P. truncatus in improved and traditional granaries

\subsection{Rate of Increase of $P$. truncatus (LGB) with Maize Variety}

Infestation of grain by $P$. truncatus was observed three months after fumigation in on hybrid maize (SC 513). $P$. truncatus infestation was noted five months after fumigation on traditional maize variety (Hickory King). The rate of increase of LGB was high in the hybrid variety as compared to the traditional variety (Figure 3). The final count of the pest in the storage systems showed a significant difference in the population densities.

\subsection{Statistical Analysis}


Table 5. ANOVA data on influence of variables on insect prevalence

\begin{tabular}{|l|l|l|l|l|l|}
\hline Source & Type 3 Sum of squares & df & Mean square & F & Sig \\
\hline Corrected model & $2869.400 \mathrm{a}$ & 79 & 36.322 & 5.946 & .000 \\
Intercept & 2747.267 & 1 & 2747.267 & 449.757 & .000 \\
Farmer & 280.608 & 4 & 70.152 & 11.485 & .000 \\
Duration & 1871.067 & 7 & 267.295 & 43.759 & .000 \\
Treatment & 308.267 & 1 & 308.267 & 50.467 & .000 \\
Framer*duration & 113.058 & 28 & 4.038 & .661 & .901 \\
Framer*treatment & 65.442 & 4 & 16.360 & 2.678 & .034 \\
Duration*treatment & 192.067 & 7 & 27.438 & 4.492 & .000 \\
Farme**duration*treatment & 38.892 & 28 & 1.389 & .227 & 1.000 \\
Error & 977.333 & 160 & 6.108 & & \\
Total & 6594.000 & 240 & & & \\
Corrected Total & 3846.733 & 239 & & & \\
\hline
\end{tabular}

a. R Squared $=.0746$ (adjusted R Squared $=.620$ )

\section{Discussion}

\section{a. On-farm storage structures}

The most commonly used on-farm storage structures are the pole and dagga granaries. The least used are the intermediate traditional granaries. [16] In Makonde District, storage granaries act as household food security system. However, the structures used for storing the food grains have been found to be of poor quality. The high rate of traditional granary use could be as a result of lack of proper building materials and knowledge, and skills. [4] According to Kapuya et al most households have inherited the use of these traditional granaries from their forefathers. [9] Since most farmers grew up in rural communities, they have also adopted the use of these traditional granaries. As indicated from the results, on-farm grain storage is going through a revolution. [4] Farmers are still faced with challenges of costs of granary maintenance. Mutangadura and Norton noted that most farmers in rural communities are faced with challenges of adopting new technologies. [12] Therefore results obtained suggest that there is slow rate of adoption of new storage technologies by smallholder farmers in Makonde District. Farmer perceptions indicated that traditional granaries gave effective storage of grains such as maize, millets and sorghum from ground moisture, insects and termites in the past. Hence they preferred to renovate their granaries than adopting new storage technologies.

Results also suggest that the evolution in the storage structures indicates a gradual change in the building materials used for granary construction. The general design has been found to be the same in all the granary types.

\section{b. The most prevalent insect pests of stored maize in Makonde District}

The most common insect pests found in stored maize were Sitophilus zeamais, Sitotroga cereallela and $P$. truncatus (LGB). These pests are primary pests that have the ability to attack wholesome grain without difficulties and therefore can survive in storage. According to Golob, and Hodges LGB is primarily more adapted to feeding on grain on the cobs than in stores. [6,7] This suggests the fact that therefore their multiplication rate was limited during storage. According to Ayertey et al, growth and multiplication of $P$. truncatus in storeage is slow when grain is predominated by weevils [1].

\section{c. Re-infestation test of improved and traditional granaries}

Re-infestation was noted three months after fumigation in both storage granaries. This could be as a result of poor design and building materials used to construct the granaries. Traditional granaries made of wooden poles and dagga have been found be having cracks inside, outside, and underneath the granary. [4] These cracks could have acted at hiding places for most pests. Also there the process of fumigation could have not been so effective. The $P$. truncatus was found to be having the the capacity to bore wooden materials, doors, and door frames. The pest could have escaped during the disinfestations process. Sitotroga cereallela was found to be re-infesting the granaries first. This could be as a result of its flying characteristics [6].

Traditional granaries normally are constructed without a ceiling. Pests which land on the roof could easily attack the stored grain. FAO reported that most insect hide in roofing materials and re-infest the stored grains. [4] Sitophilus zeamais and Sitotroga cereallela are known to inhabit their food sources. Their rapid re-infestation could as a result of the presence of their food source in the granaries. Studies carried out by McFarlane concluded that the natural environment is a food source for the $P$. truncatus. [10] Sources for S. zeamais could be nearby fields or granaries from the neighboring households in the area. Hence effective control of the insect pests requires a compulsory participation of all members of the community.

Re-infestation of $P$. truncatus to the storage systems could have been caused by the presence of the pest in its sources. These sources include the natural environment and building materials. The pest could have been living in wooden poles and thatched roofs. The pest has the ability to fly and this characteristic enables it to infest even grains at long distances. Research work carried out by concluded that LGB attraction to the scent of maize and migrates to infest the grain [6].

The rate of multiplication noted of the pest might be caused by temperature, relative humidity, and grain moisture content. The $P$. truncatus pest has the capacity to reproduce at temperatures between $23^{\circ}-25^{\circ} \mathrm{C}$ and at moisture contents as low as 9\%. [10] This makes the pest survive most conditions and is therefore difficult to control using one technique. An Integrated Pest Management approach was found to be the most recommended control measure for LGB. The presence of LGB in the granaries in Makonde District might be due to the climatic conditions which are favourable to their survival. Nyambo carried research and concluded that the pest was able to breed and multiply at the stated temperatures and relative humidity of as low as $51 \%$ [13].

The multiplication of LGB in the improved granaries could have been caused by the absence of an aeration system. The granary could easily heat up due to heat 
energy produced from the respiration of grains and pests. This tends to increases temperature and relative humidity. The increase in temperature and moisture content as a result of insect infestation could create a favourable environment of pest multiplication [15].

\section{d. Rate of increase of LGB in improved and traditional granaries}

The significant difference on the rate of increase of LGB in the two types of granaries could have been caused by the differences in the construction materials. According to Nyambo LGB was found to be present in granaries made of 16 tree types in Kenya. ${ }^{13}$ The significance could be explained by the released of maize scent from traditional granaries that attracts LGB. Improved granaries were constructed with a roof and the maize was completely covered with no aeration. The exponential shape of the graphs suggests that at lower levels pest were adapting to their new environment.

\section{e. Re-infestation on maize varieties}

The results have shown that there are significant differences in the rate of increase of the LGB pest with the varieties. The hybrid varieties have been reported to have soft kennels as compared to the traditional varieties, therefore are prone to attack by the storage pests [18].

\section{Materials and Methods}

\subsection{Study Area}

The study area was Makonde District, $\left(17^{\circ} 21^{\prime} \mathrm{S}\right.$ and $30^{\circ} 12^{\prime} \mathrm{E}$ ) which is located at the northwest of Harare in Zimbabwe. Makonde District is a farming district with a total of 20 wards which receives an average of 750 to
$1050 \mathrm{~mm}$ of rainfall per year. The average annual temperature is $26^{\circ} \mathrm{C}$. The area has typical Savannah vegetation with scattered trees in the grasslands. The area is occupied by small holder farmers who practice subsistence farming and small-scale commercial farmers. Crops grown include maize, cotton, and tobacco.

\subsection{Research Design}

The research used different sampling techniques at every stage. Firstly a pilot survey was conducted using questionnaires to determine the most common storage structures most common insect pests of stored maize in Makonde District of Mashonaland West Province of Zimbabwe. Multistage cluster sampling was used to come up with ten small holder farmers, five with traditional granaries and five improved granaries. Multistage cluster sampling involves construction of clusters and then deciding on the elements to use within the clusters. ${ }^{5}$ In this case, the wards in the district were the clusters and elements were selected from these clusters. The purposive non-probability sampling was also used to choose farmers with either traditional or improved granaries in the District. The purposive or judgmental sampling technique is the deliberate choice of an informant based on the qualities the informant possesses. [19] Five blocks were identified in the experimental design. Each ward represented a block with a pair of farmers; one with improved granary and the other with traditional granary for removing climatic barriers to the experiment. In blocks numbered one and two the farmers stored the traditional variety of Hickory King and the rest of the blocks were used for storing hybrid variety of SC 513. Treatments were repeated to increase the sample size of the experiment.

Table 6. Experimental Design

\begin{tabular}{ccc}
\hline Blocks & Treatment A (Improved granaries) & Treatment B (Traditional granaries) \\
\hline 1 & Hickory King & Hickory King \\
2 & Hickory King & Hickory King \\
3 & SC 513 & SC 513 \\
4 & SC 513 & SC 513 \\
5 & SC 513 & SC 513 \\
\hline
\end{tabular}

\section{Determination of the Most Prevalent Insect Pests of Granary - Stored Maize}

\subsection{Selection of the Farmers}

The first step was to select ten wards from the 20 wards in which these farmers were found. The second step was to purposively select farmers, ten with traditional and ten with improved granaries in these wards. Questionnaires containing both open and closed-ended questions were developed. These were augmented with personal interviews for the illiterate. The questionnaires contained items investigating the most important insect pest of stored maize in the granaries in the district and also the grain history in terms of the pesticides that have been used. There were pre-tests to the questionnaires before the actual administration by experts in entomology and rural agricultural research surveys in the Plant Quarantine Services and AGRITEX Department. The farmers who had an encounter of the storage pest $P$. truncatus were sought for permission to use their granaries for the purpose of the research through personal consent. All the farmers approached agreed to have their granaries used for the purpose of the research.

\section{Data Collection}

After three months of storage, samples were collected for analysis on a fortnight basis for four months of storage beginning from January 2012 to April 2012. Bulk samples of $5 \mathrm{~kg}$ were randomly drawn from the granaries using a multi-compartmented bulk probe. The bulk samples were mixed using a mechanical divider. Working samples of $1 \mathrm{~kg}$ were obtained and then analyzed for insect pests by sieving using a $6 \mathrm{~mm}$ sieve tray.

\section{Conclusion and Recommendations}

In Makonde District, traditional granaries are mostly used by smallholder farmers. Traditional granaries were 
been found to be prone to Prostephanus truncatus infestations as compared to improved granaries. Granaries should be built in sunny areas on cleared land three metres away from the nearest building. In humid areas, granaries should be raised off the ground at least $1.2-1.6 \mathrm{~m}$ and the grain fumigated. The recommended granary for smallholder farmers in the Makonde district is the improved granary. There is need to hold special training programmes and campaigns in which various stakeholders can be invited and contribute their expertise. Such programmes can highlight to farmers the nature and impact of post harvest losses that are due to storage pests particularly the LGB.

The $P$. truncatus has a tendency of feeding during the night and in the dark. It is recommended that the interior of the granary be painted white. It is also recommended that the storage structure must be fitted with small air vents to allow the circulation of air.

The poles have to be treated with chemicals which are pest resistant and also fire resistant. This will protect them from being bored by this destructive pest and also from veld fires.

The approach to reduce the problem of storage pest is comprehensive and requires an integrated approach called the Integrated Pest Management. The approach is a combination of various strategies which work together for a common objective of reducing post harvest losses. It also considers every production step which will have influence later in the storage of the crop that is grown. It therefore begins with the selection of a variety that is resistant to storage pest. The maize should not take too long in the drying crib as the most dry grains develop lines if weaknesses which in turn can increase susceptibility of attack by the LGB.

The storage structure has to be plastered both in and outside to close all the cracks and crevices which might provide a habitat for the insect pest. Before the loading of the new maize in storage, all the old grain has to be removed and treated again with insecticide; the store should be thoroughly cleaned of all residual grains and dust. The new grains also should be treated with insecticide before being loaded into the store so as to eliminate field fungi which might later on develop into mycotoxins and aflatoxins [11].

The stored maize has to be constantly inspected for infestation and taking appropriate measures whenever an infestation has been found.

\section{References}

[1] Ayertey, J.N., Meikle, W.G., Borgemeister, C., Camara, M. and Markham, R.H, Studies on predation of Prostephanus truncatus (Horn) (Col., Bostrichidae) and Sitophilus zeamais (Mots.) (Col., Curculionidae) at different densities on maize by Teretriosoma Entomology, 123, 265-271, 1999.

[2] Boxal, R.A, A critical review of the methodology for assessing farm-level grain losses after harvest: Tropical Development and Research Institute Report, 191, 1986.
[3] Chakraverty, A, Post Harvest Technology of Cereals, Pulses and Oilseeds, $3^{\text {rd }}$ edition. Oxford and IBH Publishing Company Pvt. Ltd, New Delhi, 2004.

[4] FAO, FAO/ World Bank workshop on reducing post-harvest losses in grain supply chains in Africa: Lessons learned and practical guidelines, 2010.

[5] Giorlando, M, Sampling in a suitcase: Multistage Cluster Sampling Made easy: Teaching Sociology, 20(4), 285- 287, 1992.

[6] Golob, P, On-farm post-harvest management of food grains: A manual for extension workers with special reference to Africa. FAO: Agricultural and Food Engineering Training and Resource Material, 1991.

[7] Hodges, R.J, The Biology and Control of Prostephanus truncatus (Coleoptera: Bostrichidae)-A destructive Storage pest with an increasing range: Journal of Stored Products Research 22(1), 114, 1986.

[8] Kamanula, J., Sileshi, G.W., Belmain, S.R., Sola, P., Mvumi, B.M., Nyirenda, G.K.C., Nyirenda, S.P. and Stevenson, P.C, Farmers' insect pest management practices and pesticidal plant use in the protection of stored maize and beans in Southern Africa: International Journal of Pest Management, 57(1),41-49.

[9] Kapuya, T., Saruchera, D., Jongwe, A., Mucheri, T., Mujeyi, K., Tramb, N.T. and Meyer, F, The Grain Industry Value Chain in Zimbabwe. Prepared for the Food and Agricultural Organisation of the United Nations, 2011.

[10] McFarlane, J.A, Pest Management Strategies for Prostephanus truncatus (Horn) (Coleoptera: Bostrichidae) as a pest of stored maize grain: Present Status and Prospects: Tropical Pest Management, 34(2), 121-132, 2008.

[11] Mhiko, T.A., An Investigation to Determine Effects and Causes of Storage Conditions on the Quality of Silo-Stored Wheat in Zimbabwe: Springer Link Journal, Natural Products and Bioprospecting, 2, 21-28, 2012.

[12] Mutangadura, G. and Norton, G.W, Agricultural research priority setting under multiple objectives: an example from Zimbabwe: Agricultural Economics, 20, 277-286, 1999.

[13] Nyambo, B.T, Post-harvest maize and sorghum grain losses in traditional and improved stores in South Nyanza District, Kenya: International Journal of Pest Management, 39(2), 181-187, 2008.

[14] Plant Protection Research Institute, 2011. Handbook of Current Analysis and Data. Vol 1.

[15] Richter, J., Biliwa, A., Helbig, J. and Helbig, S.H, First Release of Teretriosoma nigrescens Lewis (Col. Histeridae), the predator of Prostephanus truncatus (Horn) (Col. Bostrichidae) and follow-up investigations in southern Togo: Journal of applied Entomology, 122, 383-387,1998.

[16] Richter, J., Biliwa, A. and -Helbig, H.S, Losses and pest infestation in different maize storage systems with particular emphasis on Prostephanus truncatus (Horn) (Col., Bostrichidae) in Togo: Umweltschutz, 70, 112-116, 1997.

[17] Stathers, T.E., Riwa, W., Mvumi, B., Mosha, R., Kitandu, L., Mngara, K., Kaoneka, B. and Morris, M, Do diatomecious earths have potential as grain protectants for small-holder farmers in sub-Saharan Africa? The case of Tanzania: Crop Protection, 27(1), 44-70, 2008.

[18] Tadele, T., Kampiu, F., Groote, H., Hellin, J., Mugo, S., Kimenju, S., Beyene, Y., Bodhupalli, P.M., Shiferaw, B. and Banziger, M, The metal silo: An effective grain storage technology for reducing post-harvest insect and pathogen losses in maize while improving smallholder farmers' food security in developing countries: Crop Protection, 30, ( 2) 240-245, 2011.

[19] Tongco, M.D.C, Puposive Sampling as a Tool, for Information Selection: Ethnobotany Research and Applications, Vol. 5, 147158, 2007.

[20] Wambugu, R.W., Mathenge, P.W., Auma, E.O. and Rheenen, H.A Efficacy of Traditional Maize (zea mays L.) Seed Storage Methods in Western Kenya: African Journal of Food, agriculture, Nutrition and Development, 9(4). 1110-1128, 2009.

[21] Zinyengere, N., Mhizha, T., Mashonjowa, E., Chipundu, B., Geerts. and Raes, D, Using seasonal climate forecasts to improve maize production decision support in Zimbabwe: Agricultural and Forest Meteorology, Vol. 151(12), 2011, 1792-1799, 2009. 